\title{
Utilization of Technology for Mathematical Talks. An Alarming Situation
}

V.V.Peller

I believe all mathematicians will agree that over the last ten years the percentage of mathematical talks given by means of a computer presentation has jumped and is still rising. I find this situation alarming. I have the strong opinion that this tendency leads to a degradation of the quality of talks and discredits the idea of mathematical talks.

Unfortunately, it is not rare for the organizers of mathematical conferences to write to the participants to encourage them to give a computer presentation or, even worse, they inform speakers that there will be no blackboards at all. On many occasions I have asked the organizers why they do not provide blackboards. They always responded that the conference would be held in a hotel (or another place) that has no blackboards. I do not find this explanation satisfactory. I strongly believe that if they want to organize a conference, it is their responsibility to provide blackboards. No excuse is acceptable. Incidentally, twenty years ago most conferences were held at universities, while presently it is more common to organize conferences at hotels.

Once I was invited to give a seminar talk and I was informed that there would be no blackboards and that I should prepare a computer presentation. I said that was absolutely impossible. Moreover, I said that it is as if you invite a pianist to give a performance, but unfortunately you have no piano and you encourage the pianist to record the notes onto a flash drive for their computer to be able to reproduce the notes. After my words, a blackboard was found.

V. V. Peller is professor of mathematics at Michigan State University. His email address is pe11er@math.msu.edu.

The author is partially supported by NSF grant DMS 1001844.

DOI: http://dx.doi.org/10.1090/noti940

\section{Is a Mathematician a Performer or a Composer?}

Once when giving a talk at a conference, I mentioned the above comparison with inviting a pianist and not having a piano. One mathematician disagreed with my comparison; he said that a mathematician is a composer, not a performer.

I strongly disagree with his opinion. When a mathematician proves theorems, he is a composer. However, when he gives mathematical talks, he is a performer. Mathematicians should not underestimate the importance of being a performer.

\section{What is Wrong with Computer Presentations?}

Most speakers who give a computer presentation completely lose control over the speed of the presentation. They switch the screen very frequently, and they completely forget that the audience needs time to digest the information and to comprehend the material. As a result, it is very difficult (or even impossible) to follow the speaker.

Once I attended a plenary one-hour lecture. During the lecture the speaker stated all his results for the last three years and all the results of his students for the last three years. The speaker switched the screen over a hundred times. Needless to say, it was absolutely impossible to grasp the picture. Usually, when the speaker loses the audience, he does not realize it. He watches the screen and does not care about the audience.

Very often the speaker takes the PDF file of his paper designed for publication and displays it on the screen. This is a complete disaster: the speaker understands that it is impossible for the audience to read all the paper, he wants to skip certain slides, and he moves the material back and forth trying to find a page that he wants to concentrate on. The effect is disastrous. The only thing the audience can get from such a lecture is blinking screens.

Sometimes the speaker displays material with detailed text. At the same time, he talks and gives 
a verbal explanation of the material but his words do not coincide with the text on the screen. Apparently, he believes that people can read the text on the screen and listen to another text at the same time. As for me, I am not able to do two such things simultaneously.

Even if the speaker is considerate of the audience, goes at a reasonable speed, and thoroughly prepares the slides, there are still certain things that create problems for the audience. For example, when the speaker switches the screen, everything on the previous screen is gone. However, it is often important for people in the audience to look at a formula on the previous screen again. Sometimes speakers combine the computer and the blackboard and write important things on the blackboard. This can improve the presentation. However, this leads to the following problem: to read the screen, the lights are turned off; when the speaker writes on the blackboard, the lights are turned on. This can be very distracting.

Another problem is that when the speaker shows the new screen, everything on the screen appears at the same time. This is awkward. It is much easier to comprehend the material if the contents of the screen appears gradually, at a speed at which it can be digested. It is true that sometimes speakers using computers renew the screen in small portions. This can slightly improve the quality of the presentation. Nevertheless, it is still impossible to display a complicated formula gradually. However, for the audience, it is much easier to digest the material if a formula appears on the screen gradually.

I strongly believe that at least to a certain extent the talk should be an improvisation. The speaker should not lose the audience; he has to have feedback from the audience. The feedback should help the speaker adjust the speed of the presentation and decide whether he can include everything in the talk that was planned or whether to omit certain parts of the talk (or, something very, very rare, to add some material). As Paul Halmos said in $[\mathrm{H}]$, "The faces in the audience can be revealing and helpful: they can indicate the need to slow down, to speed up, to explain something, to omit something." It is very difficult to achieve this if you give a computer presentation. Once the file is prepared, the speaker cannot alter it during the talk.

Let me also mention some technical problems. From time to time (usually such things happen at least once at each conference) the speaker brings a flash drive, inserts it into the computer, and the computer for some (mysterious) reason does not want to work with his file. Sometimes it takes ten to thirty minutes to fix the problem. Another common technical problem is pop-ups that appear on the screen. The speaker desperately attempts to delete them, often asking for assistance.
I do not want to say that all computer presentations are bad. There are exceptions. There are speakers who can minimize the negative features of computer presentations. However, if they were to use their skills to give a talk at the blackboard, the result would be better. I certainly do not want to say that all blackboard talks are good. Not at all! There are speakers who give blackboard talks very poorly. However, I am 100 percent sure that if those speakers were to give computer presentations, the result would be even worse.

\section{Why Do People Want to Give Computer Presentations?}

I think that, for many mathematicians, the idea of giving a computer presentation is attractive because they believe that it is easier for them to prepare a written text and then follow that text during the talk. Some speakers feel more confident if they prepare a computer talk, and they believe that they have already completed the job. The remaining part is easy: just follow the file prepared on the computer. This is certainly a wrong perception. The speaker must think about what is best for the audience, not for himself.

Also, many mathematicians give the same talk on several different occasions. In this case, they only need to prepare the talk once.

Several mathematicians told me that they believe that computer talks have an advantage because, they say, the fact that the speaker prepared a computer talk implies that he prepared himself for the talk. I strongly disagree with this opinion. On the contrary, it is often the case that the speaker, having prepared a computer talk, believes that he is all set, which is often wrong. Even if the file is prepared, the most important and difficult task is to speak in front of the audience.

I have heard from various mathematicians that for plenary lectures they use the blackboard, while in the case of short communications they have to give computer presentations because otherwise they have no chance of covering all the material. Again, this is a wrong perception. They can certainly cover more material in a computer presentation, but this does not mean that people in the audience will be able to digest the material. It is unnecessary to cover everything related to the subject of your talk. You have to select the material that can be understood by the audience and get the audience interested in what you are doing. People who become interested in your work can learn the details later. To attract people to your research, it is not a good idea to tell them everything you can in twenty minutes. I am afraid that in this way you will instead repel the audience from your work. In this respect I would like to quote Paul Halmos [H]: "If someone told you, in half an hour, the meaning of each ideogram on a page of Chinese, could you then read and enjoy 
the poem on that page in the next half hour?" The speaker should not try to give too much detail. Sometimes, instead of writing complicated formulae or giving sophisticated definitions, it is more appropriate to describe verbally what one is doing.

Sometimes speakers try to give detailed proofs of certain results and believe that they do not have enough time for the proof if they give a blackboard talk. The same objection applies. It is not appropriate to give too many details during the talk.

\section{Is the Overhead Projector a Better Alternative?}

My opinion is that overhead projector talks are slightly better than computer presentations. Usually speakers who use overhead projecting don't violate the speed limit as badly as certain speakers who give computer presentations. It is much less common among users of overhead projecting to display their papers designed for publication. However, with some speakers the speed is still excessive; when the screen is changed, everything on that screen is gone forever and the audience has no chance to review the contents of that screen. When the lecture room has two overhead projectors, the speaker can keep some important parts of his talk on one screen and change the contents of the other screen. This can slightly improve the quality of the presentation.

However, my opinion is that there are still many disadvantages of overhead projecting. Let me again quote Paul Halmos: "Do not, ever, greet an audience with a carefully prepared blackboard (or overhead projector sheets) crammed with formulas, definitions, and theorems. (An occasionally advisable exception to this rule has to do with pictures-if a picture, or two pictures, would help your exposition but would take too long to draw as you talk, at least with the care it deserves, the audience will forgive you for drawing it before the talk begins.) The audience can take pleasure in seeing the visual presentation grow before its eyes-the growth is part of your lecture, or should be." I entirely agree with his opinion.

\section{Is It Good When Students Teach Their Professors?}

I heard from several colleagues that they never prepare computer presentations. However, occasionally when they had joint results with their students, the students gave computer talks and then sent the computer files to their professors. Later the professors themselves gave computer talks using the files of their students. This is ridiculous! Instead of teaching students how to give talks, professors are taught by their students.

Recently I attended a computer presentation at a conference. After the talk a student of the speaker, being in the audience, said that the speaker gave a computer presentation for the first time in his life: he had given only blackboard talks before. The student was very proud of his professor and proposed to congratulate him on this occasion. I do not think that such congratulations were a good idea.

It is common for young people to have a desire to master a modern technology. Sometimes this is good (in particular, it is certainly good to be able to prepare a mathematical paper with the help of a computer). However, this is not always the case. For example, young children should not use calculators to perform arithmetical operations, while college students should not use sophisticated calculators to differentiate elementary functions.

\section{Our Old Friend the Blackboard}

I strongly believe that the blackboard is the best medium for mathematical talks. It has many advantages over computer presentations or overhead projecting. On the other hand, I do not know any disadvantage (I speak from the point of view of people in the audience; the speaker can say that for him it is more convenient to prepare a computer presentation). Whatever can be performed with the help of a computer or overhead projector can also be performed much better on the blackboard.

First of all, the speed of a blackboard presentation is limited by the speed of writing on the board. I do not want to say that it is impossible to speak too fast. It is, however not to the same extent as many speakers do with computer presentations.

Next, the speaker does not have to erase the material as frequently as computer speakers switch the screen. It is certainly much better if the lecture room has several big blackboards. In this case the speaker can erase the contents of a board very rarely, and in the case of short communications there is no need to erase anything from the boards. Even if the speaker has to use an eraser, he can reserve one of the blackboards for the material that will not be erased during the talk.

What else? I have already said that the audience can digest the material much better if the material appears visually and gradually. It is much more difficult to comprehend the material if a large portion of it is suddenly displayed.

Finally, many computer (or overhead projector) speakers always look at the screen. The speaker at the blackboard does not look at the screen. He can watch the audience instead. As a result, he can have better contact with the audience, can have feedback from the audience, and can be sure that he has not lost the audience. As I have already said above, having good contact with the audience allows the speaker to adjust the speed of presentation and the amount of material to be presented. All of this is very important.

Again, let me repeat that not all blackboard talks are good talks. The speaker has to know how to use the advantages of the blackboard to be able to give a good talk. Nevertheless, I have no doubt that 
the percentage of good blackboard talks is much higher than the percentage of good computer (or overhead projector) talks.

\section{What Can Be Done to Rescue Conferences?}

This is a tough question. My opinion is that only the blackboard should be used for mathematical talks. I know that some mathematicians will call me an extremist. However, even if the mathematical community is not ready to get rid of computer presentations, there are several steps that can be taken.

First of all, I think mathematicians who use computers to give talks should ask themselves why they do it. Perhaps they have no reason other than that it is more convenient for them to prepare a computer presentation. If this is the only reason, they should think about the audience rather than their own convenience. If they do it because otherwise they will not be able to cover all the material, they should understand that by using a computer they can increase the speed of the presentation, but they cannot increase the speed of comprehension.

I think it would be a good idea for Ph.D. advisors to teach their students how to give talks and to explain to them that if they learn how to give good talks at the blackboard, they will produce a much better impression on the audience, which will help their career.

Finally, I believe that the mathematical community ought to agree on a strict rule: organizers of conferences must provide several blackboards to each lecture room. Also, the organizers of conferences should by no means encourage participants to give computer presentations.

Acknowledgment. I would like to thank Nicholas Young for reading the manuscript and for making helpful suggestions.

\section{References}

[H] P. HALmos, How to talk mathematics, Notices Amer. Math. Soc. 21 (1974), 155-158.

\section{Is It Too Late to Learn Mathematics? Minority and Nontraditional Students Show There Is a Second Chance}

\section{Estela A. Gavosto}

The typical comment when someone discovers that you are a mathematician is either "I was horrible in math" (the most common one) or "I wish I had taken more mathematics." For many it may not be too late.

All students start learning mathematics at an early age and those who typically succeed in

Estela A. Gavosto is associate professor of mathematics and associate director of the Office for Diversity in Science Training at the University of Kansas. Her email address is gavosto@math.ku.edu.

Members of the Editorial Board for Doceamus are: David Bressoud, Roger Howe, Karen King, William McCallum, and Mark Saul.

DOI: http://dx.doi.org/10.1090/noti931 mathematics-intensive careers complete their formal math education while they are young too. Mathematics is the most commonly accelerated science subject during the $\mathrm{K}-12$ years and the students who are talented in mathematics advance quickly in an intellectually nurturing environment. A common belief is that those who have mathematical talent will "display" it early in their lives and they will be properly tracked. International studies [10], however, show that in other countries a larger percentage of students than in the United States is identified as mathematically talented. That is, there is potentially a larger segment of the U.S. population with mathematical 
talent than the one that we currently identify and train.

America's prosperity in the twenty-first century is often linked to the capability of maintaining a leadership role worldwide in science and technology (see [4] and [12]). This matter brings to the forefront the need for improving $\mathrm{K}-12$ science and mathematics education. In this article we will address the issue of students who at some point showed mathematical talent but either left mathematics or never pursued a career in mathematicsintensive majors. Should they resume their math studies later in their lives? We believe they should, and demographics and the math pipeline show that we need them to do so. Moreover, we will describe one approach that we have been developing to address this challenge.

\section{Not Enough STEM Students Overall, Especially from Underrepresented Groups}

According to the National Science Board's Science and Engineering Indicators 2012 ([8]), the percentage of science and engineering degrees (excluding social and behavioral sciences) among the degrees in all fields granted to U.S. citizens and permanent residents did not change during the decade 2000-2009. During this period, the percentage of bachelors' degrees in all fields earned by American Indian/Alaska Native, African American, and Hispanic students (URMs) increased slightly from 17 percent to 19 percent, while their percentage of science and engineering degrees remained steady at approximately 15 percent. However, these percentages could be misleading and show that, despite efforts to increase their involvement, the participation of underrepresented groups in STEM disciplines is not growing fast enough. This data does not reflect the changes in demographics, since the percentage of these underrepresented groups among the population in the eighteen- to twenty-four-year-old group has increased to 33 percent (2008 statistics, [9]). In particular, the data corresponding to Hispanics could be easily misinterpreted. The number of degrees awarded to Hispanics has increased substantially but their representation in science and engineering has not changed. The work in [6] states that underrepresented minorities, or URMs, are only two-thirds as likely as whites to earn bachelors' degrees in STEM within six years, despite similar interest when they enter college. In mathematics the situation is even worse. The percentage of degrees awarded to URMs among those who have completed bachelors' degrees in the subject has decreased from 14 percent in 2000 to 12 percent in 2009. In addition, Bressoud [1] points to the recent alarming decrease in the number of bachelors' degrees in mathematics that are being awarded to African American students.
The analysis of this data is complex and poses many questions and challenges. We should also look at the numbers in mathematics not in isolation from other disciplines, but rather in the context of all the programs and opportunities that exist for underrepresented minorities in the sciences and engineering. Examples of these opportunities are the programs of the Division of Training, Workforce Development, and Diversity from the National Institute of General Medical Sciences [2]. These programs promote research training and the development of a strong and diverse biomedical research workforce. In general, the mathematical community does not have as many resources as other disciplines to recruit URMs. It is well known that other science and engineering programs welcome students with mathematical talent. These students often receive degrees in areas where they are recruited early on in their careers with offers of undergraduate research experiences and other resources. Many other socio-economic factors play a role, too, and steer students to other fields. In fact, during the period 1989-2008, the greatest increase in science and engineering bachelors' degrees earned by underrepresented minorities has been in the fields of social, computer, and medical sciences; see [9].

\section{Tapping into Nontraditional Students}

Demographics show that current attempts to modify our pipeline are not producing changes as fast as they are needed. As we improve the curriculum paths for the future, we must also find alternative new models and strategies that provide reentry points for the wide portion of the population for whom the mathematics pipeline has not functioned.

The most common definitions of nontraditional students (see Kim [5]) include considerations of age, background (such as socio-economic status, ethnicity, first generation, and employment status), and at-risk characteristics. The nontraditional population forms the largest subset of students in the nation according to a recent report to the U.S. Congress and Secretary of Education by the Advisory Committee on Student Financial Assistance [11]. In particular, this report recommends a federal initiative to generate projects examining how to educate older adults in the sciences, engineering, technology innovation, and applied mathematics. Another report from the National Academy of Sciences [12] advocates that the federal government should give tax credits to employers who help their employees pursue continuing education in science and technology. The students included in these reports have a wide range of educational needs. A disproportionately high number of underrepresented minorities could be labeled as nontraditional students according to [5]. They often first enroll in public two-year 
colleges after high school [9], resulting in a longer path to a degree with lower chances of succeeding. Any well-thought-out project would have to target a subset of the students and address common circumstances.

Among all minority and nontraditional students, we want to focus here on the group of students who took more than one calculus course (in high school, community college, or college), succeeded in them, and stopped studying mathematics at a later point. This is a large number of students; see [6] for a complete profile. Later in their lives some of these students see the need for a stronger background in mathematics and regret not having it. We will not discuss in detail how they arrive at this situation, but one common path is through AP Calculus in the high school. The high school instruction may not always provide formal mathematical depth, but very often the delivery is engaging. When the students come to a typical university, they commonly encounter the reverse situation: the instruction requires a much higher level of symbolic and conceptual skills but does not engage them enough. Another similar path occurs when students transfer between institutions with different expectations. As already mentioned, a large percentage of minority students start their college education at a community college or similar institution and, when they transfer, they often encounter mathematics curricula with a different structure of courses than at their original institutions.

\section{How Can We Train Nontraditional Students?}

For the past three years we have been teaching the experimental course Transitions in Mathematics, which addresses this challenge, at the University of Kansas. We originally designed a course for minority students who either transferred or decided late in their training to pursue a math-related major or a research career that requires significant use of mathematics. We soon found out that the course was also very suitable for a wider range of nontraditional students. The project is supported by the National Institutes of Health and the University of Kansas through KU Initiative for Maximizing Student Development (IMSD). ${ }^{1}$

Nontraditional students have a myriad of previous experiences and often are highly motivated to learn. They like to know "the why" or the meaning of a new topic and prefer to learn in task-oriented ways. Their drive gives them the focus and desire to control their learning. These attributes are assets for the learning process according to the theory of learning described by Donovan and Bransford [3]. In fact, the characteristics of nontraditional

\footnotetext{
${ }^{1}$ IMSD at Kansas University is funded by National Institutes of Health grant \#R25GM62232 from the National Institute of General Medical Science.
}

students can be mapped into this theory's learning principles: engaging prior understanding, providing learning opportunities for factual knowledge and conceptual understanding, and stimulating a metacognitive approach.

The design of Transitions in Mathematics is based on the above learning principles and it is taught in a studio format. Instead of starting over and taking sequences of courses with content that the students partially know, our course assists the students to fill the main "holes" in their background and teaches them how to gain the necessary knowledge to tackle new mathematical challenges in the future. The course starts with a math assessment, surveys, and interviews with each of the students. Based on the collected information, an individualized project grounded in the student's prior mathematical knowledge and life experiences is designed. The project outcomes are in tune with the future needs of the student. Parallel to the project, a concept map is constructed representing the connections between all the topics that the student will need to learn to complete the project. The students do worksheets in these topics to master the necessary skills and concepts. They are also introduced to a range of mathematical software and their proficient use is encouraged. The class meets at a media room or at a computer lab. The students work on their projects or worksheets individually and we foster collaboration among them. There is no formal lecture and the instructor and a graduate student assistant interact with the students giving feedback on their work. In every class period, the students give oral presentations on their current work and receive comments from the rest of the class on their conceptual understanding. The training in career development tools (library/databases search skills, public speaking, etc.) also increases long-term learning autonomy. The projects completed by the students cover a wide range of subjects. For example, they have included both applied and theoretical topics such as numerical solutions of diffusion equations for drug delivery, wavelet-based characterization of vertebral trabecular bone structure, and approximation theory in Lipschitz spaces.

Teaching the course has provided us with a collection of projects and a complex and interesting educational landscape. We are noticing patterns of topics and paths and eventually we could develop course material to be shared with others. Collaborating with faculty mentors in other departments is essential in developing meaningful applications. We have observed that traditional placement measures, like previous courses and their grades, do not dictate as much as in other settings what the students end up doing. Motivation is the most important factor in determining the students' progress, so having clear individualized goals in terms of a research project or more advanced courses is 
key to the mathematical growth of the students. Overall, the students are very appreciative of the opportunity that Transitions in Mathematics gives them. Often they expressed that they have never learned so much mathematics in a course before. The ultimate goal of the initiative is to prepare students to complete a Ph.D. in a biomedical research area (which includes mathematics) and we track all the students after they have taken our course. Up to this point, two-thirds of the students who have completed our course and graduated have been admitted to graduate programs.

Transitions in Mathematics provides a rewarding and engaging experience where we challenge the students and ourselves to learn mathematics and its applications in alternative ways. Different backgrounds and experiences are equalized when we have to learn something that we do not know. As the median age of the population in the U.S. and in many regions of the world increases, older students, striving to learn the mathematics that they did not learn in their first college experience, inspire us to reach for new frontiers in areas of mathematics outside our comfort zone. Certainly, there is a second chance to learn mathematics at a higher level.

Acknowledgment. The author would like to thank the reviewers of this article for valuable comments and suggestions.

\section{References}

[1] D. M. BRESSOUD, Trends in race/ethnicity and gender representation in the mathematical sciences, February 1,2012 . Available at http://1aunchings.blogspot.com/2012/02/trends-inraceethnicity-and-gender.htm1].

[2] Division of Training, Workforce Development, and Diversity, National Institute of General Medical Sciences, National Institutes of Health, http://www. nigms. nih.gov/About/Overview/twd.htm.

[3] M. S. DONOVAN and J. D. BRANSFORD, editors, How Students Learn Mathematics in the Classroom, National Research Council, The National Academies Press, Washington, 2005.

[4] Engage to excel: Producing one million additional college graduates with degrees in science, technology, engineering, and mathematics, report by the President's Council of Advisors on Science and Technology, February 7, 2012. Available at http:// www.whitehouse.gov/administration/eop/ostp/ pcast/docsreports.

[5] K. A. KIM, ERIC review: Exploring the meaning of nontraditional at the community college, Community College Review 30 (2002), 74-89.

[6] R. Koenig, Minority retention rates in science are sore spot for most universities, Science 324, no. 5933 (2009), 1386-1387.

[7] National Research Council, Appendix F: Ingredients for Success in STEM, Expanding Underrepresented Minority Participation: America's Science and Technology Talent at the Crossroads, Washington, DC, The National Academies Press, 2011.
[8] National Science Board, Science and Engineering Indicators 2012, Appendix Table 2-19: Earned bachelor's degrees, by citizenship, field, and race/ethnicity: 2000-2009, Arlington, VA, National Science Foundation (NSB 12-01). Available at http://www.nsf.gov/ statistics/seind12/.

[9] National Science Foundation, Division of Science Resources Statistics, Women, Minorities, and Persons with Disabilities in Science and Engineering, 2011. Special Report, NSF 11-309. Arlington, VA. Available at http://www.nsf.gov/statistics/wmpd/

[10] OECD (2010), PISA 2009 Results: What students know and can do: Student performance in reading, mathematics and science (Volume I), http://dx . doi . org/10.1787/9789264091450-en

[11] Pathways to success: Integrating learning with life and work to increase national college completion, a report to the U.S. Congress and Secretary of Education, Advisory Committee on Student Financial Assistance, Washington, DC, February 2012.

[12] Rising Above the Gathering Storm: Energizing and Employing America for a Brighter Economic Future, Committee on Prospering in the Global Economy of the 21st Century: An Agenda for American Science and Technology, National Academy of Sciences, National Academy of Engineering, Institute of Medicine, ISBN: 0-309-65442-4, 592 pages, 2007. 